\title{
Novel methods for predicting gas-particle partitioning during the formation of secondary organic aerosol
}

\author{
F. Wania ${ }^{1,2}$, Y. D. Lei ${ }^{1,2,3}$, C. Wang ${ }^{1,2}$, J. P. D. Abbatt ${ }^{2}$, and K.-U. Goss ${ }^{4,5}$ \\ ${ }^{1}$ Department of Physical and Environmental Sciences, University of Toronto Scarborough, 1265 Military Trail, Toronto, \\ Ontario, Canada \\ ${ }^{2}$ Department of Chemistry, University of Toronto, Toronto, Ontario, Canada \\ ${ }^{3}$ Department of Chemical Engineering and Applied Chemistry, University of Toronto, Toronto, Ontario, Canada \\ ${ }^{4}$ Department of Analytical Environmental Chemistry, UFZ-Helmholtz Centre for Environmental Research, \\ Permoserstraße 15, Leipzig, Germany \\ ${ }^{5}$ Institute of Chemistry, University of Halle-Wittenberg, Kurt-Mothes-Straße 2, Halle, Germany \\ Correspondence to: F. Wania (frank.wania@utoronto.ca)
}

Received: 7 August 2014 - Published in Atmos. Chem. Phys. Discuss.: 20 August 2014

Revised: 5 November 2014 - Accepted: 10 November 2014 - Published: 11 December 2014

\begin{abstract}
Several methods have been presented in the literature to predict an organic chemical's equilibrium partitioning between the water insoluble organic matter (WIOM) com-

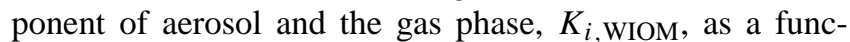
tion of temperature. They include (i) polyparameter linear free energy relationships calibrated with empirical aerosol sorption data, as well as (ii) the solvation models implemented in SPARC and (iii) the quantum-chemical software COSMOtherm, which predict solvation equilibria from molecular structure alone. We demonstrate that these methods can be used to predict $K_{i \text {,WIOM }}$ for large numbers of individual molecules implicated in secondary organic aerosol (SOA) formation, including those with multiple functional groups. Although very different in their theoretical foundations, these methods give remarkably consistent results for the products of the reaction of normal alkanes with $\mathrm{OH}$, i.e.

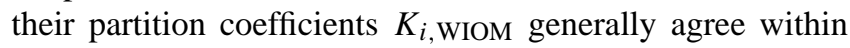
one order of magnitude over a range of more than ten orders of magnitude. This level of agreement is much better than that achieved by different vapour pressure estimation methods that are more commonly used in the SOA community. Also, in contrast to the agreement between vapour pressure estimates, the agreement between the $K_{i \text {,wIOM estimates }}$ does not deteriorate with increasing number of functional groups. Furthermore, these partitioning coefficients $K_{i, \text { WIOM }}$ predicted SOA mass yields in agreement with those measured in chamber experiments of the oxidation of normal
\end{abstract}

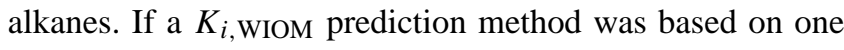
or more surrogate molecules representing the solvation properties of the mixed OM phase of SOA, the choice of those molecule(s) was found to have a relatively minor effect on

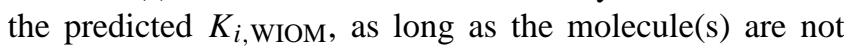
very polar. This suggests that a single surrogate molecule, such as 1-octanol or a hypothetical SOA structure proposed by Kalberer et al. (2004), may often be sufficient to represent the WIOM component of the SOA phase, greatly simplifying the prediction. The presented methods could substitute for vapour-pressure-based methods in studies such as the explicit modelling of SOA formation from single precursor molecules in chamber experiments.

\section{Introduction}

In order to understand the growth of organic particles in the atmosphere and the yield of secondary organic aerosol (SOA) formation, it is necessary to know the equilibrium partition coefficients between aerosol and gas phase at different temperatures for a large number of atmospheric oxidation products (Hallquist et al., 2009). For a chemical $i$ this coefficient can be defined as

$$
K_{i, \mathrm{P}}=\frac{C_{i, \text { Particles }}\left(\mathrm{mol} \mathrm{m}^{-3}\right)}{C_{i, \text { Gas }}\left(\mathrm{mol} \mathrm{m}^{-3}\right)} .
$$




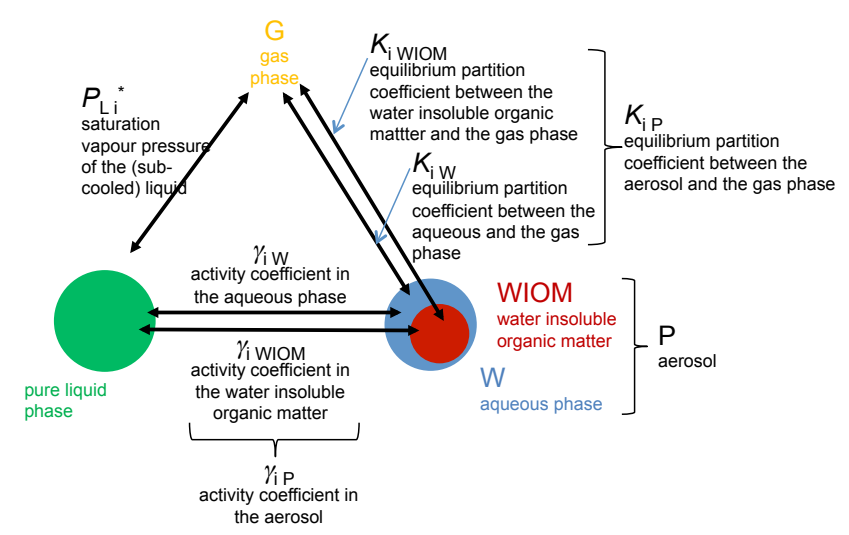

Figure 1. Thermodynamic cycle as it relates to the partitioning to atmospheric aerosol.

The Supplement contains text explaining how this definition of $K_{i, \mathrm{P}}$ relates to other commonly used versions of the gasparticle partition coefficient. Aerosol may often be composed of more than one phase, for example an aqueous phase and a phase made up largely of organic matter. Such phase separation is predicted to occur under many atmospheric conditions, except under very humid conditions (Zuend et al., 2010). It is also supported by observational evidence (You et al., 2012) and by laboratory measurements of the partitioning of a diverse set of organic chemicals to several field-collected aerosol at variable relative humidity (Arp et al., 2008a, b). In such cases, an equilibrium partition coefficient between the gas phase and each aerosol phase potentially solvating organic compounds is required. In most cases, two such equilibrium partition coefficients will be sufficient: the Henry's law constant between water (or rather a salty solution) and the gas phase $\left(K_{i, \mathrm{~W}}\right)$ and the partition coefficients between the water-insoluble organic matter (WIOM) component of the aerosol and the gas phase $\left(K_{i, \text { WIOM }}\right)$ (Fig. 1$)$.

Experimental values for $K_{i, \mathrm{WIOM}}$ and $K_{i, \mathrm{~W}}$ are missing for most of the chemicals involved in SOA formation, because many of them have not even been synthesized. In fact, many of their physico-chemical properties are missing and need to be predicted. One way to do this is the direct prediction of the partition coefficient, which is often the approach taken to obtain $K_{i, \mathrm{~W}}$ (e.g. Raventos-Duran et al., 2010). Another wellestablished method for predicting partition coefficients relies on a thermodynamic cycle whereby the desired partitioning property is derived from two other partitioning processes that might be easier to assess. This detour, which still leads to the intended result but requires an additional intermediate step, has traditionally been chosen in the aerosol community. In particular, partitioning of a chemical between gas phase and WIOM is broken up into its partitioning between WIOM and its pure liquid phase and between its own pure liquid phase and the gas phase. The former is described by the activity coefficient of the chemical in WIOM, the latter by its saturation vapour pressure (Fig. 1).
From the definition of the activity coefficient (Raoult's law) the following relationship holds:

$K_{i, \mathrm{WIOM}}=R T /\left(\gamma_{i, \mathrm{WIOM}} \cdot p_{\mathrm{L}, i}^{*} \cdot V m_{\mathrm{WIOM}}\right)$,

where $\gamma_{i}$,WIOM is the activity coefficient of $i$ in WIOM, $p_{\mathrm{L}, i}^{*}$ is the saturation vapour pressure of $i$ in its pure liquid state $(\mathrm{Pa}), V m_{\text {WIOM }}$ is the average molecular volume of the WIOM $\left(\mathrm{m}^{3} \mathrm{~mol}^{-1}\right)$ (all parameters are valid for one specified temperature), $R$ is the ideal gas constant $\left(\mathrm{m}^{3} \mathrm{~Pa} \mathrm{~K}^{-1} \mathrm{~mol}^{-1}\right)$, and $T$ is temperature (K).

Use of the thermodynamic cycle is justified if $p_{\mathrm{L}, i}^{*}$ and $\gamma_{i}$,WIOM can be predicted more accurately and precisely than $K_{i \text {,WIOM }}$ itself. Here we will argue that due to recent progress in estimating $K_{i \text {,WIOM }}$, this is no longer the case. In much of the current literature (e.g. Seinfeld and Pandis 2006) the activity coefficient in Eq. (2) is actually ignored, i.e. it is implicitly or explicitly set equal to unity for all chemicals $i$ without any further justification. In some cases, $p_{\mathrm{L}, i}^{*}$ and/or $\gamma_{i}$,WIOM are artificially adjusted to make predictions of SOA yield fit the results of chamber experiments (Jordan et al., 2008; Chen and Griffin, 2005). When comparing activity coefficients of simple chemicals that contain functional groups prevalent in substances implicated in SOA formation (e.g. nitromethane, ethanol and 1,4-dioxane) in different organic solvents of widely variable polarity (e.g. Table 3 in Park et al., 1987), it is apparent that they can differ by more than two orders of magnitude, from 0.3 to 65 . In other words, not only is it questionable to assume a priori that unity is a good estimation for the value of $\gamma_{i, \mathrm{WIOM}}$, it is also not correct to assume that the activity coefficients of different chemicals $i$ in a given organic phase are constant. Not all attempts at describing the WIOM gas-phase partitioning equilibrium with Eq. (2) assume $\gamma_{i \text {, wIOM }}$ to be unity. In particular, various group contribution methods have been introduced to predict activity coefficients of organic molecules in defined aqueous and organic aerosol phases (Jang et al., 1997; Chandramouli et al., 2003; Zuend et al., 2008). In practice, though, this approach is limited by the lack of the empirical interaction parameters that are required for the various molecular increments of the considered chemicals.

In reality, the range of values of $\gamma_{i}$,WIOM will be narrower than two orders of magnitude, as the polarity of the WIOM phase is not likely to vary over as wide a range as the solvents considered by Park et al. (1987). Realistically, $\gamma_{i}$, wIOM can be expected to be in the range of 0.8 to 10 (Jang et al., 1997; Chandramouli et al., 2003). Assuming $\gamma_{i}$,WIOM to be 1 would then infer errors up to one log unit in the resulting $K_{i \text {,wiom }}$ value.

The second step in applying the thermodynamic cycle is the estimation of the saturated liquid vapour pressure from molecular structure using various variants of group contribution methods (Myrdal and Yalkowsky, 1997; Asher et al., 2002; Capouet and Müller, 2006; Pankow and Asher, 2008; Nannoolal et al., 2008; Compernolle et al., 2011). Although evaluation of $p_{\mathrm{L}, i}^{*}$ prediction methods has been at- 
tempted (Camredon and Aumont, 2006; Barley and McFiggans, 2010; Schnitzler and Macdonald, 2012), such efforts are compromised by the general unavailability of $p_{\mathrm{L}, i}^{*}$ data for multifunctional substances within the volatility range important for gas-particle partitioning. Even though Barley and McFiggans (2010) made an explicit effort to collect reliable experimental data for low-volatility substances, those compounds "were still some 100-1000 times more volatile than the compounds expected to contribute significantly to" organic aerosol. To get a sense of the validity of these methods, their predictions are compared with each other (Camredon and Aumont, 2006; Valorso et al., 2011). Camredon and Aumont (2006) compared predicted vapour pressures of organic compounds detected in particulate matter and noted that estimates between four methods differed "widely, sometimes by more than a factor of 100". Similarly, Valorso et al. (2011) observed discrepancies between the $p_{\mathrm{L}, i}^{*}$ predicted by three different methods for the oxidation products of $\alpha$-pinene that "range between a factor of 5 to 200 on average", whereby discrepancies "increase with the number of functional groups borne by the species". Clearly, the estimation of vapour pressure is likely to introduce even larger errors than assuming $\gamma_{i}$,WIOM to be 1 .

If we assume a standard error of a factor of 5 in the activity coefficient (if this is set to unity for all chemicals) and an standard error of at least 50 from the vapour pressure prediction (see above) then the combined standard error in predicting $K_{i, \text { WIOM }}$ from Eq. (2) easily exceeds 2 log units. An error of this size is problematic. Barley and McFiggans (2010) note that the calculation of SOA yield and composition is "extremely sensitive to changes in vapour pressure values (especially for the least volatile components) typical of the differences seen between estimation methods".

Here we introduce several methods of variable complexity and sophistication that deliberately avoid the detour via the pure liquid phase and instead directly calculate $K_{i}$,WIOM. These are the polyparameter linear free energy relationship (ppLFER) approach calibrated for organic aerosol, the SPARC (SPARC Performs Automated Reasoning in Chemistry) software, and the COnductor like Screening MOdel for Realistic Solvents (COSMO-RS). These approaches are not really new, as they have been previously presented as viable methods for predicting equilibrium partitioning into the nonaqueous fraction of organic aerosol (Arp and Goss, 2009; Götz et al., 2007). However, these approaches have yet to be discovered and adopted by the wider SOA community. We hypothesize that these methods for predicting $K_{i \text {,WIOM di- }}$ rectly are less error prone than the combination of a $\gamma_{i \text {,WIOM }}$ of 1 and a $p_{\mathrm{L}, i}^{*}$ estimated by the group contribution methods mentioned above. To demonstrate the feasibility and promise of using these methods in the context of SOA formation, we apply them here illustratively to the products of the $\mathrm{OH}$ initiated oxidation of normal alkanes in the presence of $\mathrm{NO}_{\mathrm{x}}$, which has been extensively studied in chamber experiments (Lim and Ziemann, 2005, 2009). The same comparison could be applied to other common SOA precursors and their oxidation products.

\section{Methods}

\subsection{Estimation methods}

The three methods for the prediction of the partitioning of organic vapours into the WIOM component of atmospheric aerosol are briefly introduced in the following paragraphs. All three methods require information about the sorbing SOA phase either in the form of one or more representative molecular structures (COSMOtherm and SPARC) or in the form of a calibrated equation (ppLFER approach). Availability of this information is discussed and evaluated in the papers of Arp et al. (2008a, b; Arp and Goss, 2009).

The ppLFER model is based on

$\log K_{i, \mathrm{P}}=s S_{i}+a A_{i}+b B_{i}+v V_{i}+l L_{i}+c$,

where the capital letters $S_{i}, A_{i}, B_{i}, V_{i}$ and $L_{i}$ characterize the properties of the organic solute $i$ (solute descriptors), whereas the small letters define the complementary properties of the partitioning system of interest (e.g. aerosol/gas phase). $L_{i}$ is the logarithm of the hexadecane/air partition coefficient, $A_{i}$ defines the H-bond donor properties, $B_{i}$ describes the H-bond acceptor properties, $S_{i}$ represents additional specific interactions and is referred to as the dipolarity/polarizability parameter and $V_{i}$ is the characteristic volume (Abraham et al., 1991; Abraham 1993). Arp et al. (2008a) measured $K_{i, \mathrm{P}}$ of several aerosol samples (collected in different locations and seasons), at $15^{\circ} \mathrm{C}$ for a large set of diverse organic compounds. The ppLFER system parameters $s, a, b, v, l$ and $c$ were then obtained by regressing $\log K_{i, \mathrm{P}}$ against the known solute descriptors of those compounds. $K_{i, \mathrm{P}}$ for other compounds can be predicted using Eq. (3), if their solute descriptors are known. If the descriptors are unknown, they themselves can be predicted from molecular structure with ABSOLV, a group contribution quantitative structure property relationship (ACD/Labs, Advanced Chemistry Development, Inc., Toronto, Canada), although the overall predictive accuracy can be expected to deteriorate when using predicted descriptors.

Because Arp et al. (2008b) only determined $K_{i, \mathrm{P}}$ at one temperature, their ppLFER equation predicts $K_{i, P}$ only at $15^{\circ} \mathrm{C}$. The van 't Hoff equation and an enthalpy of phase transfer between solution and gas phase can be used to adjust $K_{i, \mathrm{P}}$ to other temperatures. We use the enthalpy of gas phase sorption to polyurethane foam to approximate the enthalpy of vapour solvation in WIOM, because the former can be estimated with another ppLFER similar to Eq. (3) (Kamprad and Goss, 2007).

SPARC has been described by its developers as a mechanistic toolbox containing solvation models based on fundamental chemical structure theory. These models "include 
dispersion, induction, dipole-dipole and hydrogen bonding interactions $[\ldots]$ to describe the intermolecular interaction upon placing an organic solute molecule in any single or mixed solvent system" (Hilal et al., 2004). Rather than seeking to derive chemical properties from "first principles", the SPARC solvation models were "developed and calibrated on physical properties such as vapour pressure and boiling point, $[\ldots]$ activity coefficient, solubility, GC retention time, Henry's constant, distribution coefficients" (Hilal et al., 2004). Originally developed by the National Exposure Research Laboratory of the US Environmental Protection Agency, it is now commercial software accessible to registered users through an on-line portal (http:// archem.us:8080/sparc-web/calc). To estimate a partition coefficient, the SPARC user interface has to be supplied with the SMILES (simplified molecular-input line-entry system) strings (Weininger, 1988) for the organic solute and the solvent molecule(s), as well as the system temperature.

By combining a quantum-chemical dielectric continuum solvation model with a statistical thermodynamics treatment of surface interactions, COSMO-RS can quantify the solvation of any solute in any solvent. Calculations start with a search for low-energy conformations of the solute and solvent molecules (performed with COSMOconf, version 2.1), followed by BP-TZVP gas-phase and COSMO calculations with TURBOMOLE (version 6.0, TURBOMOLE, University of Karlsruhe \& Forschungszentrum Karlsruhe GmbH, 1989-2007, TURBOMOLE GmbH, since 2007 available from www.turbomole.com) for the complete set of conformations with full geometry optimization in the gas phase and in the conductor reference state. The gas-phase energies and COSMO files of the solute and solvent molecules that result from the TURBOMOLE calculations are then used in the COSMOtherm software (version C21_0111, COSMOlogic GmbH \& Co. KG, Leverkusen, Germany, 2010) for calculating the free energies of solvation at infinite dilution based on statistical thermodynamics. In contrast to the fundamental treatment of the electrostatic interactions, the also relevant van der Waals interactions are covered in a simple empirical approach by the software. For further details on the COSMORS theory, see Klamt (2005) and Klamt and Eckert (2000).

All three methods thus can be used to predict an organic chemical's partitioning equilibrium between WIOM and the gas phase at any temperature based solely on its molecular structure as input. All three require the use of commercial software (ABSOLV in the case of ppLFERs to determine solute descriptors). They differ in the extent to which they rely on empirical data: while a ppLFER is essentially a multiple linear regression on a set of measured data, SPARC used empirical data for calibration, and COSMO-RS relies only to a very limited extent on empirical information.

\subsection{Applying the estimation methods to the normal alkanes and their atmospheric oxidation products}

To illustrate the feasibility of using these three techniques to predict the partitioning behaviour of chemicals implicated in SOA formation, we used the $\mathrm{OH}$-initiated oxidation of normal alkanes of variable chain length in the presence of $\mathrm{NO}_{\mathrm{x}}$ as an example. The oxidation products of the C8 to C17 normal alkanes are well characterized through the chamber experiments by Lim and Ziemann $(2005,2009)$. In those chamber experiments relative humidity was extremely low $(<0.1 \%)$ suggesting that not sufficient condensable water was present in the chamber to have formed an aqueous phase separate from the organic matter. Accordingly, we estimated partition coefficients between the gas phase and an organic liquid phase $\left(K_{i, \text { WIOM }}\right)$ for 10 normal alkanes and 132 oxidation products (11 products each for octane and nonane, 15 products each for C10 to C17 alkanes), as compiled in Jordan et al. (2008). Figure 2 displays their structure, using dodecane, the $\mathrm{C} 12$ alkane, for illustration. Partition coefficients for three $\delta$-hydroxycarbonyls (RP21, AP14, AP16) were not included, because their rapid conversion into dihydrofurans should prevent them from making a significant contribution to the SOA yield (Jordan et al., 2008). The group of compounds includes substances with a variable number of functional groups, from none (ALKH) to five (UR42).

Figure 3 outlines how partition coefficients between organic matter and the gas phase at $25^{\circ} \mathrm{C}$ (the temperature of the chamber experiments) were determined with the three methods. The starting points in each case were the solute molecules' SMILES strings generated using ChemSketch (ACD/Labs, Toronto, Canada). Several variations of each method were employed.

In the case of the ppLFER approach, system constants for four different aerosols given by Arp et al. (2008b) were used to calculate the aerosol/gas partitioning equilibrium at $15^{\circ} \mathrm{C}$. They include aerosol from an urban (Berlin, Germany, winter), a suburban (Dübendorf, Switzerland, winter), a rural (Roost, Switzerland, fall) and a coastal site (Aspvreten, Sweden, spring) in Europe. These four were chosen because the measured fraction of organic matter in the aerosol samples had been reported which allowed for the estimation of an aerosol density. The partitioning equilibria for all four aerosol types were adjusted to $25^{\circ} \mathrm{C}$ using the van 't Hoff equation and enthalpies of phase transfer between polyurethane foam and the gas phase estimated with the ppLFER by Kamprad and Goss (2007). These enthalpies varied from -32 to $-153 \mathrm{~kJ} \mathrm{~mol}^{-1}$, which is in the same range as enthalpies of vaporization reported for ambient SOA (Cappa and Jimenez, 2010). Although it is unknown how well the enthalpy of polyurethane foam/gas partitioning approximates the enthalpy of WIOM/gas partitioning, an adjustment of $K_{i}$,WIOM over only $10 \mathrm{~K}$ can tolerate relatively uncertain enthalpies without incurring large errors. All solute 


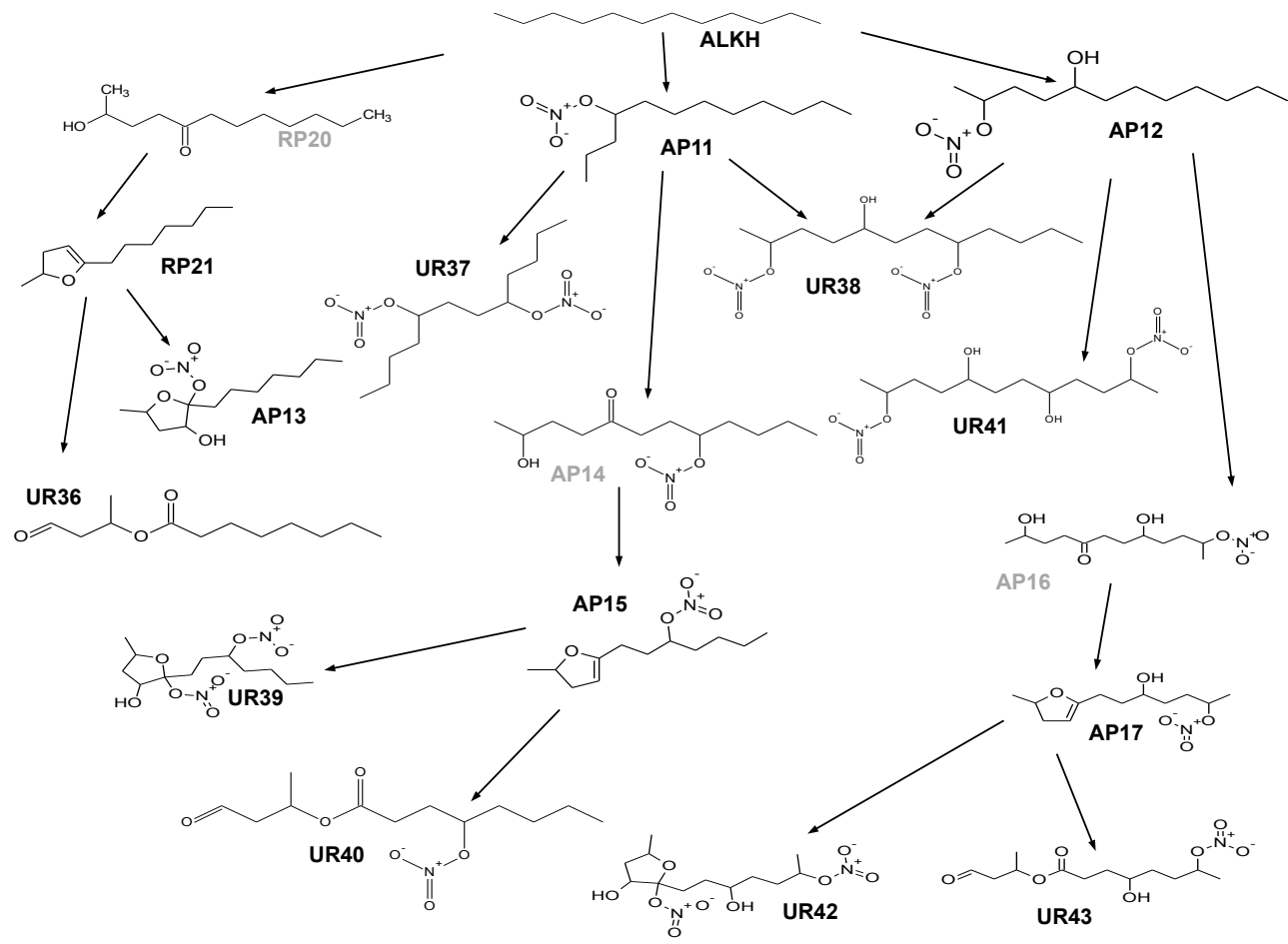

Figure 2. Molecular structures and reference codes for dodecane and the products of its oxidation by $\mathrm{OH}$. in the presence of $\mathrm{NO}_{\mathrm{x}}$ as elucidated by Lim and Ziemann (2005, 2009) and compiled by Jordan et al. (2008).

descriptors were predicted with ABSOLV. We also calculated the average $\log K_{i, \mathrm{ppLFER}}$ for the four aerosol samples.

In the case of SPARC and COSMO-RS, a phase has to be defined that represents the organic matter phase of the aerosol formed during the oxidation of the $n$-alkanes. Initially, we assumed that a single surrogate molecule can represent the solvation properties of this phase at the end of all chamber experiments (i.e. for all $n$-alkanes irrespective of chain length). Following earlier work that has suggested that the solvation characteristics of the organic matter found in atmospheric aerosol resemble those of octan-1-ol (Finizio et al., 1997; Pankow 1998) or of a hypothetical structure proposed for an oligomerization product of the oxidation of volatile aromatics (Kalberer et al., 2004; Arp and Goss 2009), we used octan-1-ol (O) and a structure termed "B" $(\mathrm{B})$ as surrogate molecules (Fig. 4). Whereas octan-1-ol has an average carbon oxidation state of -2.00 and an $\mathrm{O} / \mathrm{C}$ ratio of 0.125 , i.e. is much less oxidized than ambient organic aerosol (average oxidation state between -1.6 and +0.6 ) or the SOA formed from alkane oxidation ( -0.7 to -0.4$)$ (Kroll et al., 2011, Zhang et al., 2007), structure B's oxidation state of -0.57 $(\mathrm{O} / \mathrm{C}$ of 0.357$)$ falls within these ranges. Because these two surrogate molecules have few highly polar functional groups, we additionally calculated the partitioning coefficients from the gas phase into two organics with high $\mathrm{O} / \mathrm{C}$ ratio that have been identified as major SOA-forming products of the oxidation of $\alpha$-pinene and isoprene, respectively: 3-methyl-1,2,3-butanetricarboxylic acid (MBTCA, average carbon oxidation state $0.00, \mathrm{O} / \mathrm{C}$ ratio 0.75 ) (Szmigielski et al., 2007) and 2-methyltetrol (MT, average carbon oxidation state -0.80 , O / C ratio 0.80) (Claeys et al., 2004) (Fig. 4). We used SPARC to calculate partition coefficients from the gas phase into all four surrogates (O, B, MBTCA, MT). $K_{i, \mathrm{~B}}$ was also estimated using COSMO-RS, and $K_{i, \mathrm{O}}$ was also estimated using a ppLFER (Brown and Wania, 2009, based on equations in Goss, 2005).

Next, we assumed that the solvation properties of the organic matter phase at the end of an $n$-alkane oxidation experiment can be approximated by the solvation properties of a phase made up only of the single major oxidation product contributing to the SOA. This product, which is different for different $n$-alkanes (Table S1), was identified from the calculated SOA composition at the end of an alkane oxidation experiment when $K_{i, \mathrm{~B}}$ (SPARC) was used (for details on how the SOA composition was determined, see Sect. 2.3 below). The SMILES of the most prevalent oxidation product was entered as a "solvent" molecule in SPARC, yielding estimates termed $K_{i \text {,Abundant }}$.

In a final set of calculations, we allowed the aerosol organic matter phase to be composed of the actual mixtures of oxidation products in condensed form and used COSMO-RS to calculate the partitioning coefficients $K_{i \text {,Mix }}$ into this "solvent" mixture. In contrast to the other explored methods, this approach does not require an assumption about the molec- 


\section{polyparameter Linear Free Energy Relationship (ppLFER)}

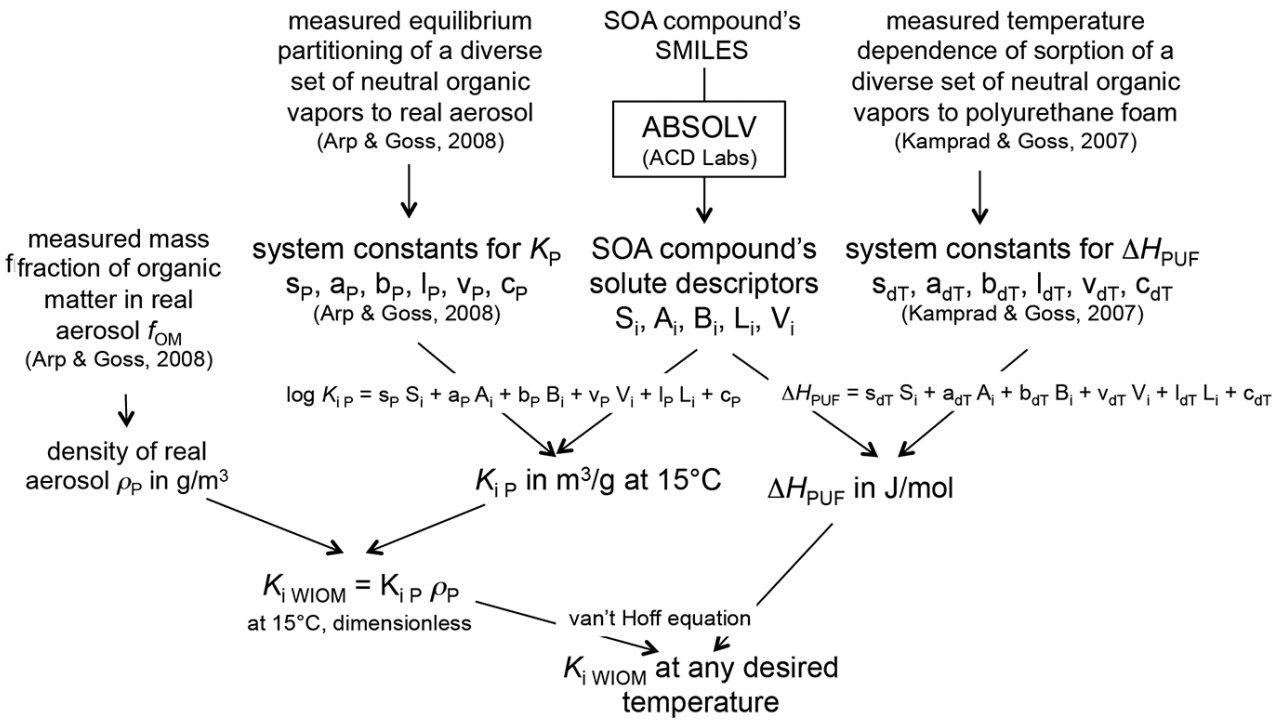

Cosmo-RS

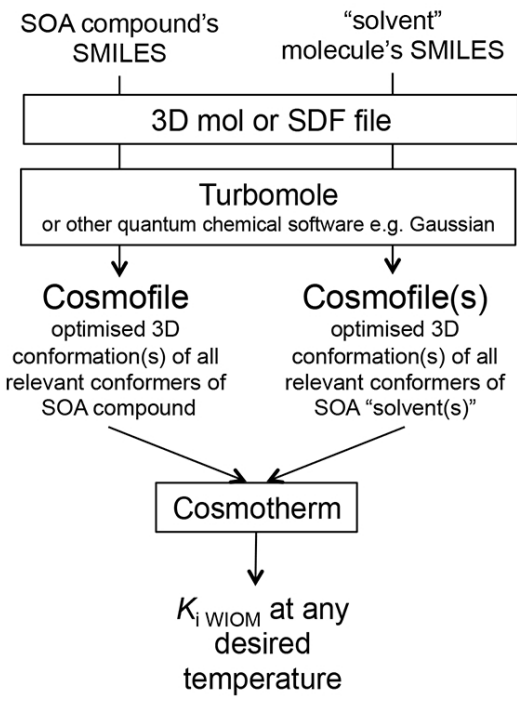

SPARC

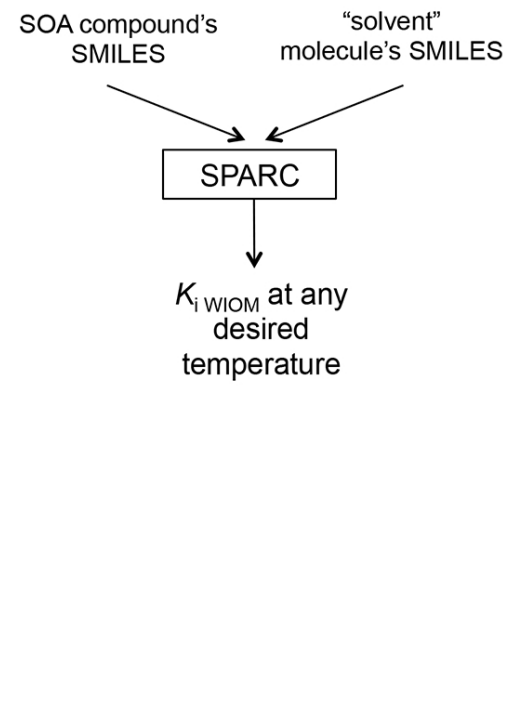

Figure 3. Outline of the three methods for estimating $K_{i}$,WIOM.

ular nature of the SOA phase. Because $K_{i \text {, Mix }}$ depends on the mixture's composition and the composition in turn depends on $K_{i, \text { Mix }}$, this required iterative calculations whereby the $K_{i, \text { Mix }}$ and the SOA composition were calculated repeatedly until neither changed significantly any longer. As the starting point of the iterations, we used the SOA composition obtained with $K_{i, \mathrm{~B} \text { (SPARC) }}$. According to our current process understanding this latter approach is closest to a realistic scenario. It is also computationally quite demanding. A more elaborate discussion of this approach will be given in a separate publication.

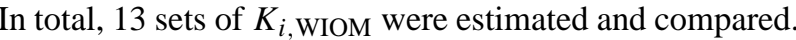
They are summarized in Table 1. They are each given a separate abbreviation to easily identify them.

\subsection{Yield calculation}

Using the Caltech Atmospheric Chemistry Model (CACM), Jordan et al. (2008) calculated the composition of the mixture of oxidation products formed at the end of each $n$-alkane oxidation experiment conducted by Lim and Ziemann (2005). They then quantified the gas-particle partitioning equilibrium of these products using estimated saturation vapour 
Table 1. Description and nomenclature for the 13 data sets for the equilibrium partition coefficient between the water-insoluble organic matter of aerosol and the gas phase $K_{i, \text { WIOM }}$ estimated with three methods. The three methods displayed in bold font are those selected for the inter-method comparison in Sect. 2.3.5.

\begin{tabular}{|c|c|c|c|}
\hline Organic matter phase is & SOA phase & Method & Abbreviation \\
\hline \multirow[t]{5}{*}{ Based on real aerosol } & Dübendorf winter & ppLFER & \\
\hline & Berlin winter & ppLFER & \\
\hline & Aspvreten & ppLFER & \\
\hline & Roost & ppLFER & \\
\hline & Average of the four & ppLFER & $\boldsymbol{K}_{i, \mathrm{ppLFER}}$ \\
\hline \multirow[t]{6}{*}{ Based on surrogates } & octan-1-ol & ppLFER & $K_{i, \mathrm{O}}(\mathrm{ppLFER})$ \\
\hline & octan-1-ol & SPARC & $K_{i, \mathrm{O}(\mathrm{SPARC})}$ \\
\hline & 3-methylbutane-1,2,3-tricarboxylic acid & SPARC & $K_{i, \mathrm{MBTCA}}$ \\
\hline & 2-methylbutane-1,2,3,4-tetrol & SPARC & $K_{\mathrm{MT}}$ \\
\hline & The Kalberer et al. structure B & SPARC & $\boldsymbol{K}_{i, \mathrm{~B}(\mathrm{SPARC})}$ \\
\hline & The Kalberer et al. structure B & COSMO-RS & $K_{i, \mathrm{~B}(\mathrm{Cosmo})}$ \\
\hline \multirow[t]{2}{*}{ Based on oxidation products } & Most abundant oxidation product in SOA & SPARC & $K_{i, \text { Abundant }}$ \\
\hline & Iteratively determined mixture of oxidation products & COSMO-RS & $\boldsymbol{K}_{i, \operatorname{Mix}}$ \\
\hline
\end{tabular}

Table 2. Mean difference (MD) and mean absolute difference (MAD) between the four sets of ppLFER-predicted $K_{i, \text { WIOM }}$ and between those four sets and their average.

\begin{tabular}{lrllrl}
\hline Comparison & MD & MAD & Comparison & MD & MAD \\
\hline Berlin vs. Dübendorf & -0.24 & 0.24 & Berlin vs. average & 0.08 & 0.12 \\
Berlin vs. Aspvreten & 0.27 & 0.40 & Dübendorf vs. average & 0.32 & 0.32 \\
Berlin vs. Roost & 0.29 & 0.29 & Aspvreten vs. average & -0.19 & 0.29 \\
Dübendorf vs. Aspvreten & 0.51 & 0.57 & Roost vs. average & -0.21 & 0.21 \\
Dübendorf vs. Roost & 0.53 & 0.53 & & & \\
Aspvreten vs. Roost & 0.01 & 0.26 & & & \\
\hline
\end{tabular}

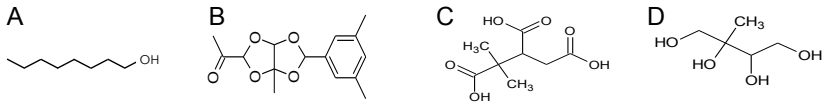

Figure 4. Structure of the four molecules considered as possible surrogates for secondary organic aerosol: octan-1-ol (Finizio et al., 1997) (a), water insoluble organic matter B (Kalberer et al., 2004) (b), 3-methylbutane-1,2,3-tricarboxylic acid (MBTCA) (Szmigielski et al., 2007) (c) and 2-methylbutane-1,2,3,4-tetrol (MT) (Claeys et al., 2004) (d).

pressures of the oxidation products and assuming that their activity coefficients in the formed SOA are 1. This allowed them to quantify the total mass of SOA formed $\left(M_{\mathrm{tot}}\right)$, which can be converted into a yield estimate by relating it to the amount of $n$-alkane present in the gas phase at the start of the experiment. Following Jordan et al. (2008), we calculated the mass and composition of SOA formed, and thus also a SOA yield (mass of SOA formed per mass of alkane initially present). However, instead of using vapour pressure, we used the equilibrium partition coefficients estimated in this study. Specifically, we calculated the amount $M_{i}$ of each compound $i$ in the SOA using (Jordan et al., 2008)

$M_{i}=C_{i} \frac{K_{i, \text { WIOM }} M_{\mathrm{tot}} / d_{\mathrm{WIOM}}}{K_{i, \text { WIOM }} M_{\mathrm{tot}} / d_{\mathrm{WIOM}}+1}$,

where $C_{i}$ is the calculated concentration of $i$ at the end of an experiment (taken from Table $2 \mathrm{a}$ in Jordan et al., 2008) and $d_{\text {WIOM }}$ is the density of the organic matter (assumed to be $1000000 \mathrm{~g} \mathrm{~m}^{-3}$ ). While initially a value of $M_{\text {tot }}$ was guessed, it was then calculated using

$M_{\mathrm{tot}}=\sum_{i} M_{i}$

Calculations with Eqs. (4) and (5) were then repeated until $M_{\text {tot }}$ no longer changed.

\section{Results}

\subsection{Comparison of predicted partitioning coefficients}

The predicted partition coefficients $K_{i}$,WIOM are compiled in an Excel sheet that is part of the Supplement. The data were compared in three steps. After comparing the partition coefficients predicted by different variants of one of the three 


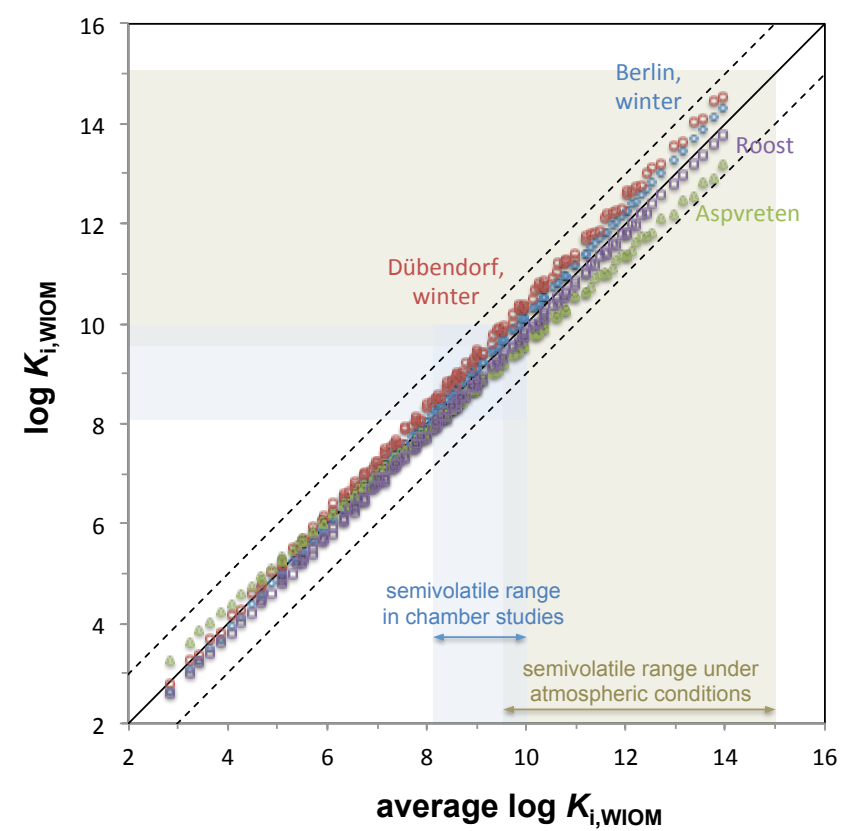

Figure 5. Plot comparing the partition coefficients at $25^{\circ} \mathrm{C}$ of alkanes and their oxidation products between the water-insoluble organic matter of aerosol and the gas phase $\left(K_{i}\right.$,WIOM $)$ predicted with four ppLFERs calibrated with empirical data for different ambient aerosol samples (Arp et al., 2008b). The blue and beige shading indicates where gas-particle partitioning of organic compounds is sensitive to the values of $K_{i}$,WIOM under conditions prevailing in chamber studies and the atmospheric environment, respectively (Lei and Wania, 2004).

methods (Sects. 3.1.1 to 3.1.3), we compared the partition coefficients for the same "solvent" surrogate predicted by different methods (Sect. 3.1.4). Finally, we compared predictions from different methods (Sect. 3.1.5). Comparison with measured data is not possible, because they do not exist.

As part of the comparison we calculated the mean difference (MD) and the mean absolute difference (MAD) between each pair of $K_{i, \text { WIOM data sets: }}$

$$
\begin{aligned}
& \mathrm{MD}_{\mathrm{XY}}=\frac{1}{n} \sum_{i}\left(\log _{10} K_{i, \mathrm{WIOMX}}-\log _{10} K_{i, \mathrm{WIOMY}}\right) \\
& \mathrm{MAD}_{\mathrm{XY}}=\frac{1}{n} \sum_{i}\left|\log _{10} K_{i, \mathrm{WIOM} \mathrm{X}}-\log _{10} K_{i, \mathrm{WIOM} \mathrm{Y}}\right| .
\end{aligned}
$$

\subsubsection{Comparison of partitioning coefficients predicted by ppLFER for different aerosol}

Arp et al. (2008b) presented ppLFER system constants for nine different ambient aerosols. We used four of them to pre-

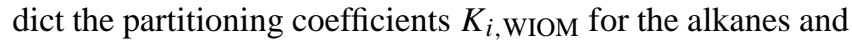
their oxidation products. They are compared in Fig. 5 by plotting them against their average. Table 2 gives the MD and MAD between the four sets of $K_{i}$,WIOM and between the four sets of $K_{i, \text { WIOM }}$ and their average.
Figure 5 and the values in Table 2 indicate that the four sets

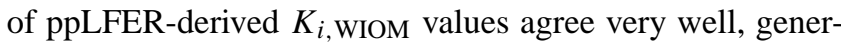
ally well within half an order of magnitude. The MAD between the two sets with the largest discrepancy (Dübendorf winter with generally higher $K_{i}$,wIOM vs. ppLFER Aspvreten with generally lower $K_{i \text {,WIOM }}$ is $0.57 \log$ units; the smallest MAD between the two urban winter aerosols (Dübendorf and Berlin) is only $0.25 \log$ units. Considering that the four aerosol samples were sampled in different seasons and at sites with very different characteristics, this level of agreement confirms a remarkable consistency in the partitioning properties or aerosol WIOM in space and time (Arp et al., 2008b). The agreement between the ppLFER-predicted $K_{i \text {,wIOM }}$ deteriorates slightly with increasing $K_{i \text {,wIOM }}$. This is not surprising, as the ppLFERs were calibrated with relatively simple and quite volatile chemicals $\left(\log K_{i \text {,WIOM }}<7\right)$ and their application to some of the $n$-alkane oxidation products with four or even five functional groups involves a considerable extrapolation.

\subsubsection{Comparison of partitioning coefficients predicted by SPARC for different surrogate "solvents"}

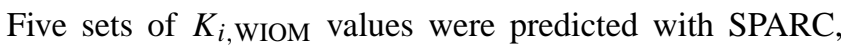
four involving different surrogate solvents (Fig. 4) and one relying on the alkane oxidation product that was predicted to be most abundant in the SOA formed during the oxidation of alkanes (Table S1 in the Supplement). They are compared in Fig. 6 by plotting four of the predictions against $K_{i, \mathrm{~B} \text { (SPARC); }}$; MD and MAD are listed in Table 3.

The three sets of SPARC predictions involving relatively non-polar surrogate solvents ( $\left.K_{i, \mathrm{O}}, K_{i, \mathrm{~B}}, K_{i, \mathrm{Abundant}}\right)$ agreed well with each other (Fig. 6), with MADs on the order of 0.25 to $0.35 \log$ units (Table 3 ). In contrast to the different ppLFER predictions (Fig. 5), there was no indication that the level of agreement depends on the range of $K_{i}$,WIOM, i.e. was more or less similar for relatively simple, volatile compounds and for less volatile chemicals with multiple functional groups. The sets of partition coefficients predicted for the two highly polar surrogate solvents $\left(K_{i, \mathrm{MBTCA}}, K_{i, \mathrm{MT}}\right)$, on the other hand, deviated very considerably from the others (Fig. 6). $K_{i, \mathrm{MT}}$ values were on average almost three orders of magnitude lower than the $K_{i, \text { WIOM }}$ calculated for relatively non-polar solvents, whereas $K_{i, \mathrm{MBTCA}}$ were on average 1.5 orders of magnitude higher. The $K_{i, \mathrm{MT}}$ were also very poorly

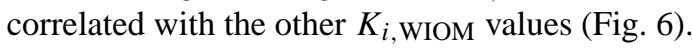

\subsubsection{Comparison of partitioning coefficients predicted by COSMO-RS}

Two sets of partitioning coefficients were predicted with COSMO-RS. One used the Kalberer et al. (2004) structure $\mathrm{B}$ as a "surrogate" solvent $\left(K_{i, \mathrm{~B}(\mathrm{COSMO})}\right)$; in the other the condensed phase had the actual composition of SOA formed by the partitioning of the alkane oxidation products $\left(K_{i, \text { Mix }}\right)$. 


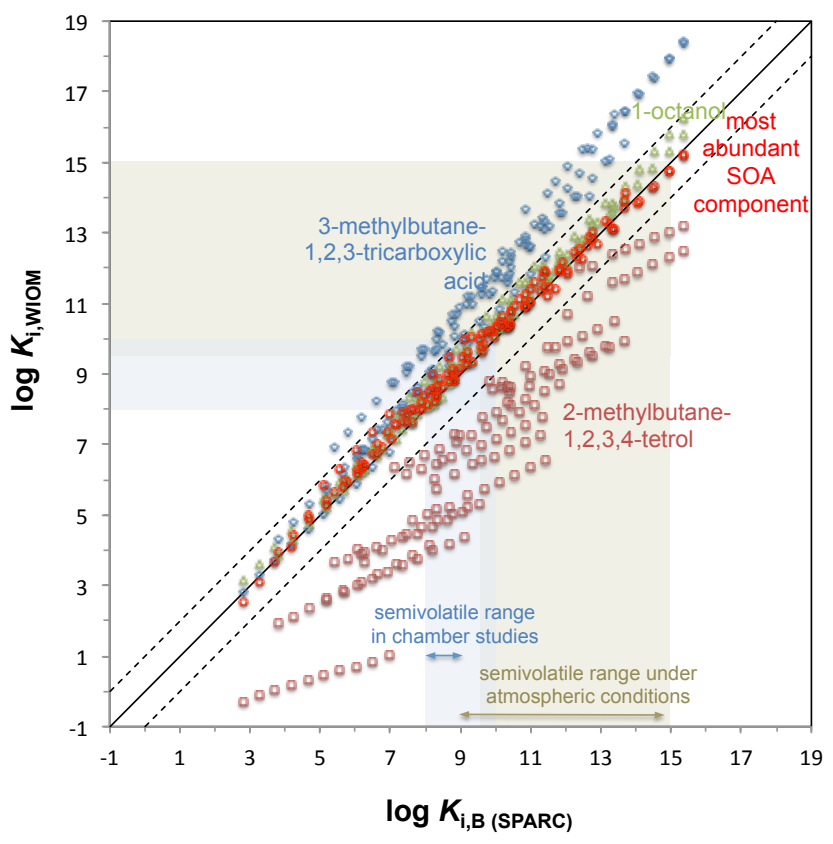

Figure 6. Plot comparing the partition coefficients at $25^{\circ} \mathrm{C}$ of alkanes and their oxidation products between different surrogate "solvents" (mimicking the partitioning properties of the water-insoluble organic matter of aerosol) and the gas phase predicted with SPARC. The $x$-axis is the partitioning coefficient for the surrogate structure B proposed by Kalberer et al. (2004).

Table 3. Mean difference (MD) and mean absolute difference (MAD) between the five sets of SPARC-predicted $K_{i \text {,WIOM }}$.

\begin{tabular}{lrr}
\hline Comparison & MD & MAD \\
\hline Structure B vs. octan-1-ol & -0.349 & 0.352 \\
Structure B vs. MBTCA & -1.496 & 1.506 \\
Structure B vs. MT & 2.768 & 2.768 \\
Structure B vs. most abundant SOA component & -0.198 & 0.260 \\
octan-1-ol vs. most abundant SOA component & 0.150 & 0.279 \\
\hline
\end{tabular}

The two sets of $K$-values were remarkably similar (Fig. 7), with a MD of only -0.13 and a MAD of $0.20 \log$ units. Again, no dependence of MD or MAD on the value of $K_{i, \text { WIOM }}$ was apparent.

\subsubsection{Comparison of partitioning coefficients for two surrogate solvents predicted by two methods}

For two surrogate solvents, we have predictions of $K_{i \text {,wIOM }}$ made by two different methods: SPARC and ppLFER were used to obtain $K_{i, \mathrm{O}}$, whereas $K_{i, \mathrm{~B}}$ was predicted with both

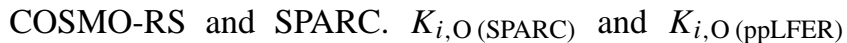
showed excellent agreement (Fig. 8), with a MD of -0.02 and a MAD of $0.31 \log$ units. Considering the uncertainty inherent in such predictions (Stenzel et al., 2014), this level of agreement amounts to essentially identical predictions. Incidentally, we also predicted $K_{i, \mathrm{O}}$ with a

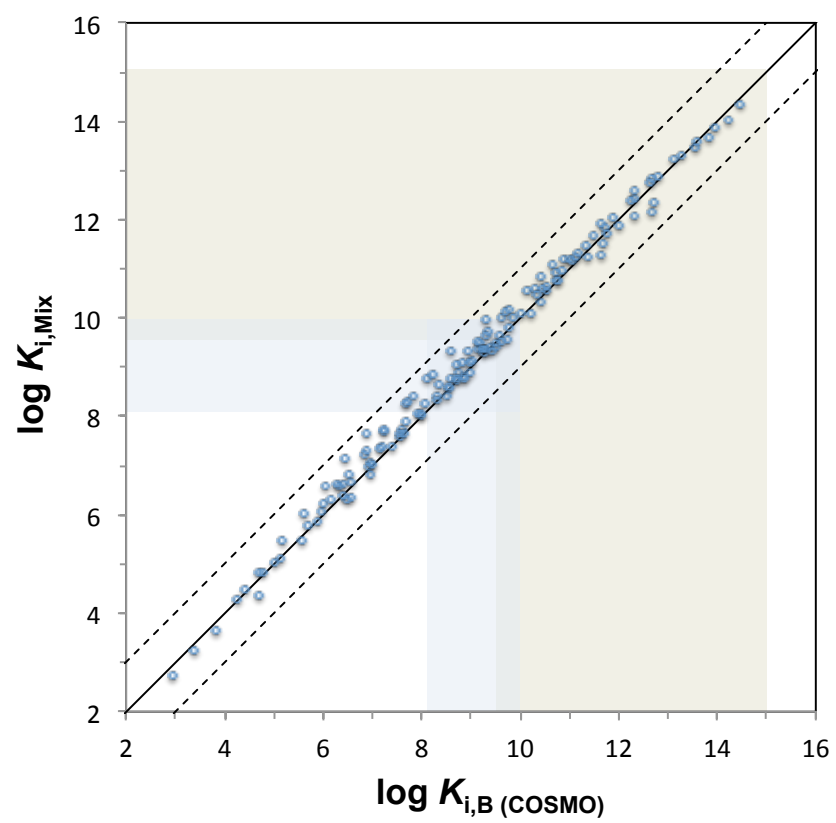

Figure 7. Plot comparing the partition coefficients at $25^{\circ} \mathrm{C}$ of alkanes and their oxidation products between the water-insoluble organic matter of aerosol and the gas phase predicted with COSMORS, using either the Kalberer et al. (2004) structure B as a surrogate solvent ( $x$-axis) or using a condensed phase with the actual composition of SOA formed by the partitioning of the alkane oxidation products.

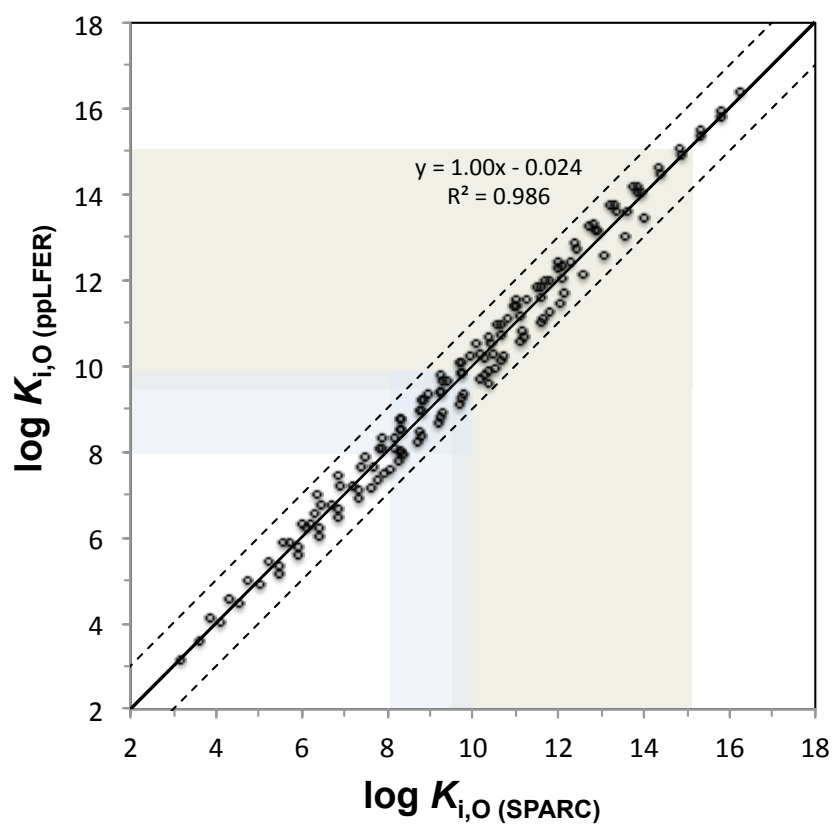

Figure 8. Plot comparing the partition coefficients at $25^{\circ} \mathrm{C}$ of alkanes and their oxidation products between octan-1-ol and the gas phase predicted with SPARC and by polyparameter linear free energy relationship. 


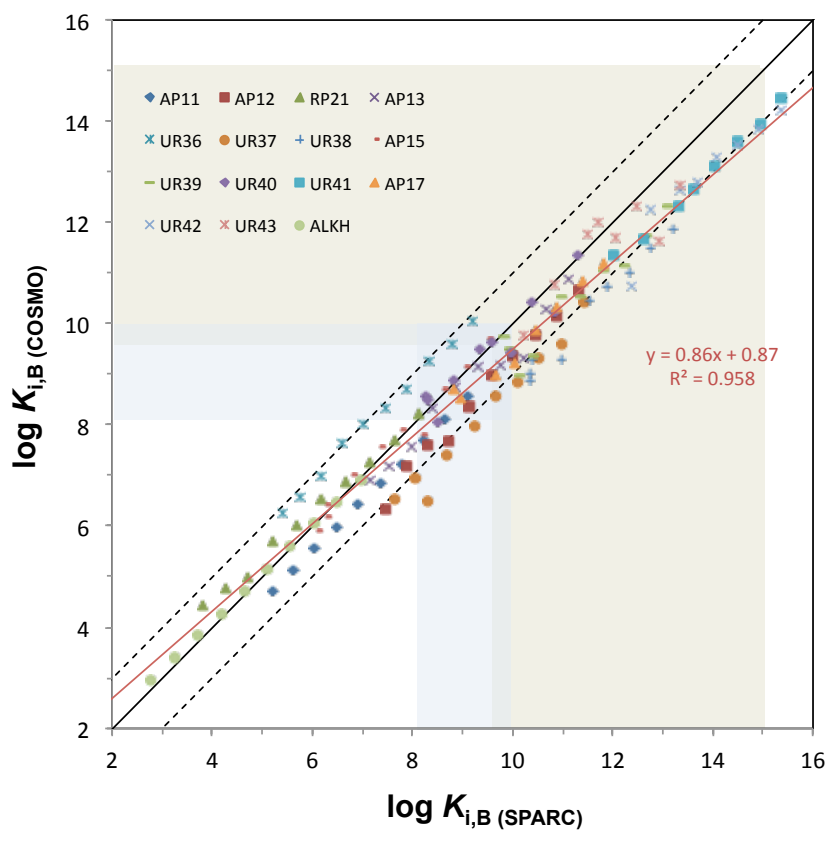

Figure 9. Plot comparing the partition coefficients at $25^{\circ} \mathrm{C}$ of alkanes and their oxidation products between the Kalberer et al. (2004) structure B and the gas phase predicted with SPARC and COSMORS. For a definition of the chemical codes in the legend, see Fig. 2.

quantitative structure property module implemented in the US EPA's EPISuite (http://www.epa.gov/opptintr/exposure/ pubs/episuite.htm), but agreement with the two sets of predictions made with SPARC and by ppLFER was much lower (Fig. S1 in the Supplement compares EPISuite and SPARC predictions), with a MAD of one order of magnitude and individual discrepancies as large as three orders of magnitude. Clearly, fragment-based property prediction methods such as EPISuite have difficulties with multifunctional organic compounds and are thus poorly suited to the kind of chemicals relevant to SOA formation.

Agreement between the SPARC and COSMO-RS predictions of the partitioning properties of the Kalberer et al. (2004) structure B was reasonable (MD of 0.42 and MAD of 0.63), but different for different types of compounds

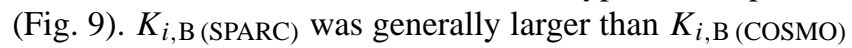
for the oxidation products with nitrate groups, especially those that have two nitrate groups (UR41, UR42, UR38, UR37), in which case the discrepancy was generally around one $\log$ unit. The largest discrepancy of $1.80 \mathrm{log}$ units was observed for decane-5,6-diyl dinitrate, i.e. the $\mathrm{C} 10$ version of UR37, which is the only compound within this class where the two nitrate groups sit on neighbouring $\mathrm{C}$-atoms. According to COSMO-RS, this results in electronic effects that polarize the $\mathrm{C}-\mathrm{H}$ bond nearby and thus create a $\mathrm{H}$-bond donor

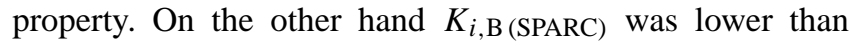
$K_{i, \mathrm{~B}}$ (COSMO) by one log unit for UR36, the only carbonyl ester without a nitrate substitution (Fig. 2).

\subsubsection{Comparison of partitioning coefficients predicted by ppLFER, SPARC and COSMO-RS}

For the final comparison we chose one set of partition coefficients from each of the three prediction methods, namely the average of the four ppLFER predictions $\left(K_{i \text {, ppLFER }}\right)$, the SPARC prediction for surrogate B $\left(K_{i, \mathrm{~B} \text { (SPARC) }}\right)$, and the COSMO-RS prediction for the actual mix of oxidation products $\left(K_{i, \mathrm{Mix}}(\mathrm{COSMO})\right)$. The three sets thus represent widely different approaches to $K_{i \text {,wIOM }}$ prediction, with respect to their reliance on empirical data (based on empirical data involving partitioning to actual aerosol samples; partially based on empirical data, but none involving aerosol OM; not reliant on empirical data), the degree of realism in treating the WIOM phase (sampled aerosol as surrogate; hypothetical structure as surrogate; actual mix of oxidation products) and the computational and time effort required. The three data sets are compared in three plots in Fig. 10.

As in the ppLFER vs. SPARC comparison of $K_{i, \mathrm{O}}$ (Fig. 8), the $K_{i, \text { ppLFER }}$ and $K_{i, \mathrm{~B}}$ (SPARC) are highly correlated $\left(R^{2}=0.99\right)$. However, $K_{i, \mathrm{~B}}$ (SPARC) is consistently higher

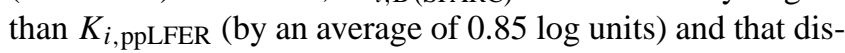
crepancy increases with increasing $K_{i \text {,WIOM }}$ (Fig. 10b). The comparisons with $K_{i, \mathrm{Mix}}$ (COSMO) (Fig. 10a, c) show larger scatter ( $R^{2}$ of 0.96 and 0.95$)$, which also mimics the poorer

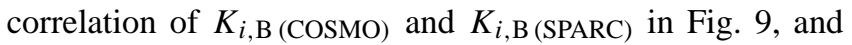
may be related to the intramolecular interactions considered by COSMO-RS. The $K_{i, \mathrm{Mix}}$ (COSMO) is generally half an order of magnitude higher than $K_{i \text {,ppLFER }}$ irrespective of the

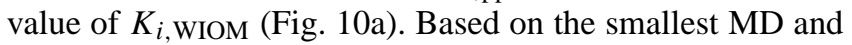
MAD, $K_{i, \text { Mix (COSMO) }}$ and $K_{i, \mathrm{~B} \text { (SPARC) }}$ show the best agree-

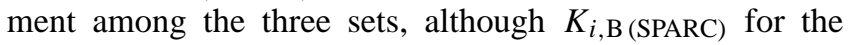
less volatile oxidation products tends to be higher than the $K_{i \text {,Mix (COSMO) }}$ (Fig. 10c). Despite the highlighting of these differences, one should, however, not lose sight of the general remarkable agreement between the three data sets: the MAD is always considerably less than an order of magnitude.

\subsection{Comparison of predicted and measured SOA yields}

SOA yields corresponding to the end of the chamber experiments of Lim and Ziemann (2005) were calculated using the total concentrations of oxidation products calculated with CACM by Jordan et al. (2008) and each set of $K_{i \text {,wIOM pre- }}$ dictions. They were then plotted against the number of alkane carbons and compared with the measured yields. Figure S2 in the Supplement shows such plots for all sets of $K_{i \text {,WIOM }}$, whereas Fig. 11 shows them only for the three sets of predictions selected for the method comparison in Sect. 3.1.5. Figure 11 also includes yields calculated by Jordan et al. (2008) using a vapour-pressure-based approach (nominal case, i.e. without adjusting vapour pressure or activity coefficients to achieve better fit).

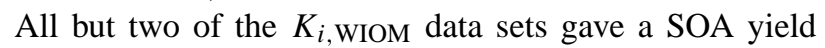
prediction that was as good as or better than the nomi- 

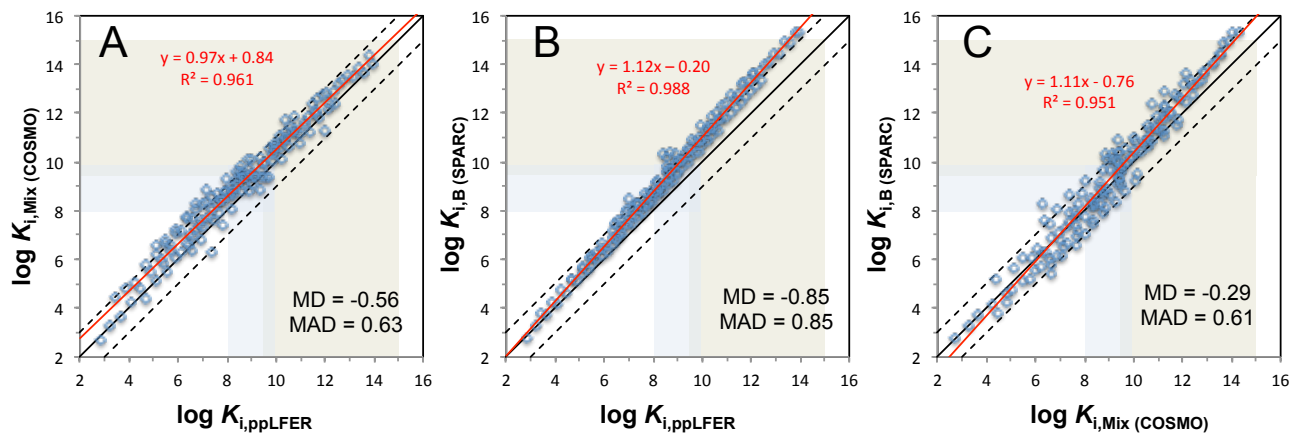

Figure 10. Plots comparing the partition coefficients at $25^{\circ} \mathrm{C}$ of alkanes and their oxidation products between the water-insoluble organic matter of aerosol and the gas phase predicted with three selected methods.

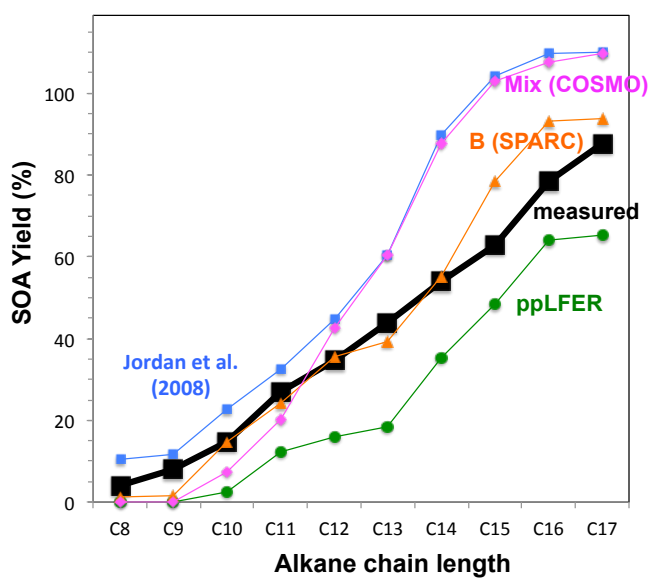

Figure 11. SOA yield from chamber experiments (black squares and line) compared to simulated results using the $K_{i, \text { WIOM data }}$ sets obtained by polyparameter linear free energy relationships (average of four, green circles), by using SPARC and the surrogate B by Kalberer et al. (2004) (orange triangles), or by using COSMO-RS and the actual composition of the simulated SOA phase (magenta diamonds). For comparison the simulated results for the nominal case by Jordan et al. (2008) are shown (blue squares). Note that yields exceeding $100 \%$ are possible because they are calculated on a mass basis (mass of SOA formed for mass of alkane initially present).

nal case by Jordan et al. (2008): $K_{i, \mathrm{MT}}$ were clearly too low and gave very low SOA yields; $K_{i, \text { MBTCA }}$ on the other hand were too high and gave SOA yields exceeding the measured ones considerably (Fig. S2 middle in the Supplement). Clearly, the highly polar surrogates MT and MBTCA do not have solvation properties resembling those of SOA formed during the oxidation of $n$-alkanes. The ppLFERderived partition coefficients gave SOA yields that are generally somewhat lower than measured, except for the ppLFER for the Dübendorf/Winter aerosol, which gave SOA yields for the longer chain alkanes that are close to the measurements (Fig. S2 left in the Supplement). Five data sets, namely $K_{i, \mathrm{O} \text { (ppLFER) }}, K_{i, \mathrm{O} \text { (SPARC) }}, K_{i, \text { Abundant }}, K_{i, \mathrm{~B} \text { (COSMO) }}$ and $K_{i, \text { Mix }}$, gave yield estimates that were similar to the Jordan et al. (2008) nominal case in that the SOA yield is overpredicted for the longer chain alkanes and flattens out for $\mathrm{C} 15$ to $\mathrm{C} 17$. The latter occurs because almost all of the oxidation products of these long chain alkanes already are particle bound. The $K_{i, \mathrm{~B} \text { (SPARC) }}$ data set gave the best SOA yield estimate, falling within the $20 \%$ uncertainty range of the measured numbers for all carbon chain lengths. However, those subtle differences in the level of agreement with the measured yields should not be over-interpreted. In fact, the good agreement between the measured and the $K_{i, \mathrm{~B}}$ (SPARC) predicted yield may to some extent even be fortuitous.

We also predicted the composition of the SOA formed in the chamber experiments for each $n$-alkane chain length using the three sets of $K_{i \text {,WIOM }}$ considered in Sect. 3.1.5. A discussion and comparison of these three predictions with the compositions calculated by Jordan et al. (2008) and measured by Lim and Ziemann (2005) is included in the Supplement.

\section{Discussion}

\subsection{Agreement between predictions of $K_{i}$, wIOM}

The MADs within methods (Sects. 3.1.1 to 3.1.3), namely 0.24 to 0.57 for ppLFER, 0.26 to 0.35 for different relatively non-polar surrogates for SPARC and 0.20 for the two COSMO-RS data sets, are similar to the MADs between methods for the same phase (Sect. 3.1.4): 0.31 for SPARC vs. ppLFER, and 0.63 for SPARC vs. COSMO-RS. Perhaps more surprisingly, the MADs between methods relying on different approaches for describing the SOA phase (Sect. 3.1.5) are only somewhat larger (0.61 to 0.85$)$.

It is noteworthy that the three comparisons involving a COSMO-RS prediction had a very similar MAD (0.61 to $0.63)$ and also showed a similar degree of scatter $\left(R^{2}\right.$ of 0.95 to 0.96 ), indicating that these discrepancies have more to do with the way the solutes are treated in COSMO-RS than with the way in which the SOA phase is described. 


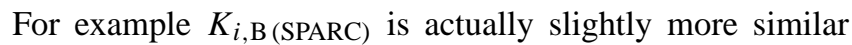
(lower MD, lower MAD, higher $R^{2}$ ) to $K_{i, \text { Mix (COSMO) than }}$

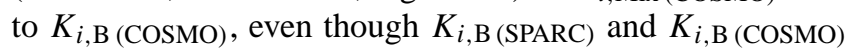
refer to the same condensed phase. In general, it appears as if the way the WIOM phase is represented is not that crucial for the partitioning behaviour of the $n$-alkane oxidation products as long as the WIOM phase is not too polar - in other words, differences between the $K_{i}$, wIOM data sets are more related to the differences in the approaches (e.g. to what degree they account for intramolecular interactions) than to the way these approaches treat the WIOM phase.

The most noteworthy aspect of the comparison of the

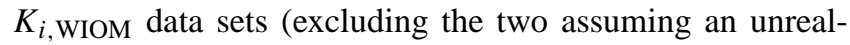
istically polar organic matter phase) is that the MADs are always less than $0.85 \log$ units. MADs and MDs for groups of $n$-alkane oxidation products with the same number of functional groups are reported in Table S2 in the Supplement. Discrepancies between different $p_{i, \mathrm{~L}}^{*}$ predictions for multifunctional chemicals of relevance in the context of SOA formation tend to be much larger (Camredon and Aumont, 2006, Valorso et al., 2011). For example, Valorso et al. (2011) noted MADs between three commonly used methods of 1.27 , 1.31 , and 0.57 for the $p_{i, \mathrm{~L}}$ of oxidation products of $\alpha$-pinene with three functional groups and MADs of 3.6, 2.23, and $1.52 \log$ units for products with more than three functional groups. This contrasts with MADs of 0.74, 0.74 and 0.64 the $\log K_{i \text {,WIOM }}$ of oxidation products of $n$-alkanes with three functional groups, and MADs of 0.55, 1.06 and 0.62 for those with four and five functional groups. The same holds for the mean bias: Valorso et al. (2011) reported MDs of -1.14 , -1.23 and -0.09 between $\log p_{i, \mathrm{~L}}$ predictions of compounds with three functional groups and MDs of $-3.59,-2.2$ and 1.39 for those with more than three functional groups. Here the mean bias ranged from -0.01 to -0.74 for compounds with three functional groups and from -0.47 to -1.06 for those with four and five functional groups. Clearly, whereas the discrepancy between the $p_{i, \mathrm{~L}}^{*}$ predictions generally increases rapidly with increasing number of functional groups, and therefore increasing relevance to gas particle partitioning, no such deterioration in the agreement of $K_{i, \text { WIOM }}$ predictions was observed. This better agreement of the $K_{i \text {,wIOM }}$ predictions is all the more noteworthy, because the compared $K_{i}$,WIOM prediction methods are conceptually much more dissimilar than the commonly employed $p_{i, \mathrm{~L}}^{*}$ prediction methods, which are for the most part group contributions methods.

What is at the root of the different performance of $p_{\mathrm{L}, i}^{*}$ and $K_{i \text {,WIOM }}$ prediction methods? Vapour pressure $p_{\mathrm{L}, i}^{*}$ (as well as other partitioning equilibria) of polyfunctional molecules strongly depends on intramolecular interactions between neighbouring functional groups. These effects lead to strongly non-linear/non-additive contributions from the various functional groups to the overall saturation vapour pressure of the complete molecule (e.g. Goss et al., 2009). In the group contribution methods that are commonly applied by the SOA community such effects can only be accounted for by empirical correction factors. For the multitude of polyfunctional chemical products that result from atmospheric oxidation reactions hundreds if not thousands of such empirical correction factors would be needed but are not and will never be available. Instead, commonly applied $p_{\mathrm{L}, i}^{*}$ estimation methods contain no more than 20 or 30 group contribution or correction factors and are thus not likely to be able to include within their applicability domain many of the reaction products making up non-aqueous SOA.

When estimating the partitioning coefficients from molecular structure, ABSOLV, which was used to obtain the descriptors needed for the ppLFER approach, and SPARC heavily depend on calibration and might thus be expected to suffer from the same problem as the vapour pressure estimation methods. However, ABSOLV and SPARC have the principal advantage of treating all types of phase partitioning of organic molecules with one unifying concept. This implies that virtually all available experimental partition coefficients could be used for calibration and derivation of group contribution and correction factors. The number of such partitioning data points likely ranges in the hundreds of thousands compared to thousands of available $p_{\mathrm{L}, i}^{*}$ data.

COSMOtherm performs thermodynamic calculations based on quantum-chemically derived input information and is thus much more fundamentally based than any of the other methods. Its performance does not depend on any calibration that would restrict its application domain to certain compound classes. This software is quite capable of covering various intramolecular effects that arise from neighbouring functional groups (Goss et al., 2009, Stenzel et al., 2014). In general, COSMOtherm yields partition coefficients in various partition systems with a root mean square error of about 0.8 log units for complex multifunctional molecules (Stenzel et al., 2014).

\subsection{Agreement between predicted and measured yields}

The good agreement of the SOA yields measured in the experiments by Lim and Ziemann $(2005,2009)$ with those obtained when applying the $K_{i}$,WIOM values predicted here is promising, but should be interpreted carefully. Alone, the fact that the predicted composition of the SOA deviates from the measured one (see Supplement), suggests this agreement to likely be to at least some extent fortuitous. For example, the CACM reaction sequence for $n$-alkanes is incomplete (Jordan et al., 2008) and likely does not include all of the oxidation products contributing to SOA in the experiments by Lim and Ziemann (2005, 2009). On the other hand, in the experiments some of the less volatile oxidation products may have sorbed to the chamber walls instead of contributing to the measured SOA mass (Matsunaga and Ziemann, 2010; Zhang et al., 2014). Nevertheless, it is noteworthy that some of the methods for predicting partitioning introduced here (in particular $K_{i, \mathrm{~B} \text { (SPARC) }}$ ) succeeded in simulating the 
measured yields better than the nominal approach (Jordan et al., 2008) based on saturation vapour pressure estimated with the method by Myrdal and Yalkowsky (1997). The latter approach was only able to predict yields within the uncertainty range of the measured ones, if the saturation vapour pressures of carbonyl esters were adjusted upwards by factors between 1 and 10, depending on the chain length of the alkane from which they were derived. This fine-tuning was justified by arguing that the carbonyl ester's presence in the simulated SOA (which contradicts the experimental findings) should be interpreted "as a proxy for the aerosol-forming products from the reaction of $\mathrm{OH}$ with the carbonylester" (Jordan et al., 2008).

We also applied our approach to simulate the SOA yield measured in chamber experiments of the ozonolysis of terpenes (e.g. $\alpha$-pinene), using the data presented in Chen and Griffin (2005). When applying SPARC-predicted $K_{i}$,WIOM of the terpene oxidation products identified and quantified by Chen and Griffin (2005), no significant formation of SOA was predicted (data not shown), even though such formation had been observed in chamber experiments. When seeking to simulate the same data, Chen and Griffin (2005) had to adjust their vapour pressures downward by as much as a factor of 1000 to predict the formation of SOA in amounts comparable to measurements. We believe that in the case of the terpenes this was necessary because the identified oxidation products did not proceed far enough. In this case the vapour pressure adjustment is representing higher-generation oxidation products. More recent attempts to model the formation of SOA from $\alpha$-pinene (e.g. Valorso et al., 2011, Zuend and Seinfeld, 2012), which rely on structures generated by models - such as the Master Chemical Mechanism (MCM) - rather than measurements and therefore include higher-generation oxidation products, confirmed that the Chen and Griffin (2005) set of compounds did likely not include the substances contributing to SOA formation. There is now also experimental evidence that much less volatile oxidation products contribute significantly to the SOA formed during the oxidation of $\alpha$-pinene (Ehn et al., 2014).

\section{Conclusions}

We believe there is sufficient reason to suggest that approaches predicting the partitioning between the organic matter of aerosol and the gas phase directly are preferable to the commonly applied methods of predicting vapour pressures and activity coefficients in the organic aerosol phase. While neither approach's accuracy can be evaluated directly because of a lack of measured partitioning coefficients and vapour pressures of multifunctional compounds in the volatility range of interest, there are several key advan-

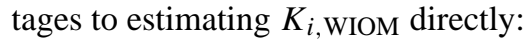

- Predicting the partitioning equilibrium of interest directly rather than through a thermodynamic triangle is conceptually simpler and therefore preferable. On a practical level, it means that only one prediction method will be required.

- Considering the lack of empirical data for relevant chemicals, property prediction methods that rely entirely or to a large extent on a calibration with empirical data (such as the $p_{i, \mathrm{~L}}^{*}$ group contribution methods or AIOMFAC for activity coefficient prediction) are bound to have severe limitations because the predictions for multifunctional chemicals will inevitably involve extensive extrapolations to areas outside the methods' domains of applicability. While SPARC and ABSOLV rely on calibrations as well, their unified conceptual design allows them to take advantage of a much larger base of empirical data. COSMO-RS almost completely avoids the need for calibration.

- We have shown here that different sets of $K_{i, \text { WIOM }}$ estimates for multifunctional organic chemicals in the range of volatility relevant to gas-particle partitioning and SOA formation agree much better with each other than different sets of $p_{i, \mathrm{~L}}^{*}$ estimates for such compounds, suggesting that $K_{i}$,WIOM for such compounds can be predicted with much greater precision than $p_{i, \mathrm{~L}}^{*}$.

- For one case study, namely the oxidation of $n$-alkanes, we have shown that the use of $K_{i}$,WIOM predicts SOA yield in agreement with experimental results obtained in chamber experiments.

We therefore recommend that models of the gas-particle partitioning of semi-volatile organic compounds generated during atmospheric oxidation processes and of the resultant formation of SOA explore the option of using predicted

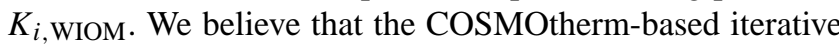

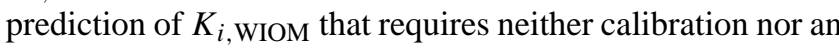
a priori assumption regarding the molecular composition of the SOA phase is the most fundamental and therefore most promising approach in the long term. However, in situations where the computational effort needs to be minimized, an approach relying on a surrogate phase will often be preferable. When using a surrogate molecule such as the Kalberer et al. (2004) B to represent the SOA phase we assume that it has solvation properties that resemble those of the SOA, even though we are aware that differently aged or sourced SOA has variable molecular composition that is possibly reflected in different solvation properties. Those using vapour pressure and an activity coefficient in WIOM of 1 assume that the SOA has solvation properties that for each compound resemble those of its own pure liquid phase. Even though both approaches therefore make simplifying assumptions about the solvation properties of the SOA, simply the considerably higher precision of the $K_{i}$,WIOM prediction compared to the

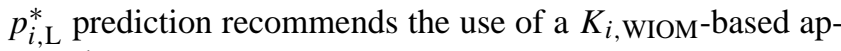
proach. 
Here we showed that the Kalberer et al. (2004) B and octan-1-ol are surrogates with solvation properties that reasonably approximate those of SOA formed from $n$-alkane oxidation. It remains to be seen whether they are equally suited to represent the solvation properties of more highly oxidized SOA, as is commonly formed from biogenic precursors, or whether different surrogates are required (e.g. those combining molecular characteristics of the highly oxidized, extremely low volatility organic compounds described in Ehn et al., 2014). Interestingly, our study suggests that the relationship between average carbon oxidation state and the polarity of a molecule/SOA phase may be quite weak: the two highly polar surrogates MT and MBTCA had different solvation properties from structure B, even though they had similar oxidation states; structure B and octan-1-ol had similar solvation properties even though they have widely different oxidation states. This may suggest that even highly oxidized SOA may not be as polar a "solvent" as might be expected (especially if it is composed of oligomers), and a single surrogate may indeed be suitable to simulate solvation properties of a wide range of ambient aerosol, possibly even highly aged and highly oxidized SOA. The remarkable similarity of the $K_{i}$,WIOM predictions obtained by ppLFERs for a wide range of ambient aerosol samples (Sect. 3.1.1) further supports this possibility.

The adoption of these prediction methods in the atmospheric research community may be encouraged by additional considerations. All three of the methods presented here not only have the capability to predict $K_{i}$,WIOM at any atmospherically relevant temperature, but can also be used to predict other parameters of relevance to gas-particle partitioning and SOA formation. This includes the partitioning of organic solutes to the aqueous phase (Goss, 2006; Raventos-Duran et al., 2010) and the effect of atmospherically relevant salts on this partitioning equilibrium (Endo et al., 2012; Wang et al., 2014). Some of the methods can also be used to predict surface sorption coefficients relevant to aerosol, including the sorption to the surface of water (Roth et al., 2002; Goss, 2009), soot (Roth et al., 2005) and different salts, including ammonium sulfate (Goss and Schwarzenbach, 1999). The prospect thus exists to predict most, if not all, of the parameters relevant to the partitioning of organic compounds to aerosol with one unified, conceptual approach.

\section{The Supplement related to this article is available online at doi:10.5194/acp-14-13189-2014-supplement.}

Acknowledgements. The authors are grateful to Carolyn Jordan and Jianjun Chen for sharing data on the calculated composition of the oxidation products in various chamber experiments. We also acknowledge financial support from the Natural Sciences and Engineering Research Council of Canada (NSERC) and a fellowship to K.-U. Goss from the German Academic Exchange Service (DAAD).

Edited by: A. Nenes

\section{References}

Abraham, M. H.: Scales of solute hydrogen-bonding: Their construction and application to physicochemical and biochemical processes, Chem. Soc. Rev. 22, 73-83, 1993.

Abraham, M. H., Whiting, G. S., Doherty, R. M., and Shuely, W. J.: Hydrogen bonding xvii. The characterisation of 24 gasliquid chromatographic stationary phases studied by Poole and co-workers, including molten salts, and evaluation of solutestationary phase interactions, J. Chromatography, 587, 229-236, 1991.

Arp, H. P. H. and Goss, K. U.: Ambient gas/particle partitioning. 3. Estimating partition coefficients of apolar, polar, and ionizable organic compounds by their molecular structure, Environ. Sci. Technol., 43, 1923-1929, 2009.

Arp, H. P. H., Schwarzenbach, R. P., and Goss, K. U.: Ambient gas/particle partitioning. 1. Sorption mechanisms of apolar, polar, and ionizable organic compounds, Environ. Sci. Technol., 42, 5541-5547, 2008a.

Arp, H. P. H., Schwarzenbach, R. P., and Goss, K. U.: Ambient gas/particle partitioning. 2: The influence of particle source and temperature on sorption to dry terrestrial aerosols, Environ. Sci. Technol., 42, 5951-5957, 2008b.

Asher, W. E., Pankow, J. F., Erdakos, G. B., and Seinfeld, J. H.: Estimating the vapor pressures of multi-functional oxygencontaining organic compounds using group contribution methods, Atmos. Environ., 36, 1483-1498, 2002.

Barley, M. H. and McFiggans, G.: The critical assessment of vapour pressure estimation methods for use in modelling the formation of atmospheric organic aerosol, Atmos. Chem. Phys., 10, 749767, doi:10.5194/acp-10-749-2010, 2010.

Brown, T. N. and Wania, F.: Development and exploration of an organic contaminant fate model using poly-parameter linear free energy relationships, Environ. Sci. Technol., 43, 6676-6683, 2009.

Camredon, M., and Aumont B.: Assessment of vapor pressure estimation methods for secondary organic aerosol modeling. Atmos. Environ., 40, 2105-2116, 2006.

Capouet, M. and Müller, J.-F.: A group contribution method for estimating the vapour pressures of $\alpha$-pinene oxidation products, Atmos. Chem. Phys., 6, 1455-1467, doi:10.5194/acp-6-1455-2006, 2006.

Cappa, C. D. and Jimenez, J. L.: Quantitative estimates of the volatility of ambient organic aerosol, Atmos. Chem. Phys., 10, 5409-5424, doi:10.5194/acp-10-5409-2010, 2010.

Chandramouli, B., Jang, M., and Kamens, R. M.: Gas-particle partitioning of semi-volatile organics on organic aerosols using a predictive activity coefficient model: analysis of the effects of parameter choices on model performance, Atmos. Environ., 37, 853-864, 2003.

Chen, J. J. and Griffin, R. J.: Modeling secondary organic aerosol formation from oxidation of alpha-pinene, beta-pinene, and dlimonene, Atmos. Environ., 39, 7731-744, 2005. 
Claeys, M., Graham, B., Vas, G., Wang, W., Vermeylen, R., Pashynska, V., Cafmeyer, J., Guyon, P., Andreae, M. O., Artaxo, P., and Maenhaut, W.: Formation of secondary organic aerosols through photooxidation of isoprene, Science, 303, 1173-1176, 2004.

Compernolle, S., Ceulemans, K., and Müller, J.-F.: EVAPORATION: a new vapour pressure estimation method for organic molecules including non-additivity and intramolecular interactions, Atmos. Chem. Phys., 11, 9431-9450, doi:10.5194/acp-119431-2011, 2011.

Ehn, M., Thornton, J. A., Kleist, E., Sipilä, M., Junninen, H., Pullinen, I., Springer, M., Rubach, F., Tillmann, R., Lee, B., LopezHilfiker, F., Andres, S., Acir, I.-H., Rissanen, M., Jokinen, T., Schobesberger, S., Kangasluoma, J., Kontkanen, J., Nieminen, T., Kurtén, T., Nielsen, L. B., Jørgensen, S., Kjaergaard, H. G., Canagaratna, M., Dal Maso, M., Berndt, T., Petäjä, T., Wahner, A., Kerminen, V.-M., Kulmala, M., Worsnop, D. R., Wildt, J., and Mentel, T. F.: A large source of low-volatility secondary aerosol, Nature, 506, 476-479, 2014.

Endo, S., Pfennigsdorff, A., and Goss, K.-U.: Salting-out effect in aqueous $\mathrm{NaCl}$ solutions: Trends with size and polarity of solute molecules, Environ. Sci. Technol., 46, 1496-1503, 2012.

Finizio, A., Mackay, D., Bidleman, T. F., and Harner, T.: Octanolair partition coefficient as a predictor of partitioning of semivolatile organic chemicals to aerosols, Atmos. Environ., 31, 2289-2296, 1997.

Goss, K.-U.: Predicting the equilibrium partitioning of organic compounds using just one linear solvation energy relationship (LSER), Fluid Phase Equilib., 233, 19-22, 2005.

Goss, K.-U.: Prediction of the temperature dependency of Henry's law constant using poly-parameter linear free energy relationships, Chemosphere, 64, 1369-1374, 2006.

Goss, K.-U.: Predicting adsorption of organic chemicals at the airwater interface, J. Phys. Chem. A, 113, 12256-12259, 2009.

Goss, K.-U. and Schwarzenbach, R. P.: Quantification of the effect of humidity on the gas/mineral oxide and gas/salt adsorption of organic compounds, Environ. Sci. Technol., 33, 4073-4078, 1999.

Goss, K.-U., Arp, H. P. H., Bronner, G., and Niederer, C.: Nonadditive effects in the partition behavior of various aliphatic and aromatic bifunctional molecules, Environ. Tox. Chem., 28, 5260, 2009.

Götz, C. W., Scheringer, M., MacLeod, M., Roth, C. M., and Hungerbühler, K.: Alternative approaches for modeling gasparticle partitioning of semivolatile organic chemicals: Model development and comparison, Environ. Sci. Technol., 41, 12721278, 2007.

Hallquist, M., Wenger, J. C., Baltensperger, U., Rudich, Y., Simpson, D., Claeys, M., Dommen, J., Donahue, N. M., George, C., Goldstein, A. H., Hamilton, J. F., Herrmann, H., Hoffmann, T., Iinuma, Y., Jang, M., Jenkin, M. E., Jimenez, J. L., Kiendler-Scharr, A., Maenhaut, W., McFiggans, G., Mentel, Th. F., Monod, A., Prévôt, A. S. H., Seinfeld, J. H., Surratt, J. D., Szmigielski, R., and Wildt, J.: The formation, properties and impact of secondary organic aerosol: current and emerging issues, Atmos. Chem. Phys., 9, 5155-5236, doi:10.5194/acp-9-51552009, 2009.

Hilal, S. H., Carreira, L. A., and Karickhoff, S. W.: Prediction of the solubility, activity coefficient, gas/liquid and liquid/liquid distri- bution coefficients of organic compounds, QSAR \& Combinatorial Science, 23, 709-720, 2004.

Jang, M., Kamens, R. M., Leach, K. B., and Strommen, M. R.: A thermodynamic approach using group contribution methods to model the partitioning of semivolatile organic compounds on atmospheric particulate matter, Environ. Sci. Technol., 31, 28052811, 1997.

Jordan, C. E., Ziemann, P. J., Griffin, R. J., Lim, Y. B., Atkinson, R., and Arey, J.: Modeling SOA formation from $\mathrm{OH}$ reactions with C-8-C-17 n-alkanes, Atmos. Environ., 42, 8015-8026, 2008.

Kalberer, M., Paulsen, D., Sax, M., Steinbacher, M., Dommen, J., Prevot, A. S. H., Fisseha, R., Weingartner, E., Frankevich, V., Zenobi, R., and Baltensperger, U.: Identification of polymers as major components of atmospheric organic aerosols, Science, 303, 1659-1662, 2004.

Kamprad, I. and Goss, K.-U.: Systematic investigation of the sorption properties of polyurethane foams for organic vapors, Anal Chem., 79, 4222-4227, 2007.

Klamt, A.: From Quantum Chemistry to Fluid Phase Thermodynamics and Drug Design, Elsevier, Amsterdam, 234 pp., 2005.

Klamt, A. and Eckert, F.: Cosmo-RS: A novel and efficient method for the a priori prediction of thermophysical data of liquids, Fluid Phase Equilibria, 172, 43-72, 2000.

Kroll, J. H., Donahue, N. M., Jimenez, J. L., Kessler, S. H., Canagaratna, M. R., Wilson, K. R., Altieri, K. E., Mazzoleni, L. R., Wozniak, A. S., Bluhm, H., Mysak, E. R., Smith, J. D., Kolb, C. E., and Worsnop, D. R.: Carbon oxidation state as a metric for describing the chemistry of atmospheric organic aerosol, Nature Chem., 3, 133-139, 2011.

Lei, Y. D. and Wania, F.: Is rain or snow a more efficient scavenger of organic chemicals?, Atmos. Environ., 38, 3557-3571, 2004.

Lim, Y. B. and Ziemann P. J.: Products and mechanism of secondary organic aerosol formation from reactions of n-alkanes with $\mathrm{OH}$ radicals in the presence of $\mathrm{NO}_{\mathrm{x}}$, Environ. Sci. Technol., 39, 9229-9236, 2005.

Lim, Y. B. and Ziemann P. J.: Chemistry of secondary organic aerosol formation from $\mathrm{OH}$ radical-initiated reactions of linear, branched, and cyclic alkanes in the presence of $\mathrm{NO}_{\mathrm{x}}$, Aerosol Sci. Technol., 43, 604-619, 2009.

Matsunaga, A. and Ziemann P. J.: Gas-wall partitioning of organic compounds in a Teflon film chamber and potential effects on reaction product and aerosol yield measurements, Aerosol Sci. Technol., 44, 881-892, 2010.

Myrdal, P. B. and Yalkowsky, S. H.: Estimating pure component vapor pressures of complex organic molecules, Ind. Eng. Chem. Res., 36, 2494-2499, 1997.

Nannoolal, Y., Rarey, J., and Ramjugernath, D.: Estimation of pure component properties: Part 3. Estimation of the vapor pressure of non-electrolyte organic compounds via group contributions and group interactions, Fluid Phase Equil., 269, 117-133, 2008.

Pankow, J. F.: Further discussion of the octanol/air partition coefficient $K_{\mathrm{OA}}$ as a correlating parameter for gas/particle partitioning coefficients, Atmos. Environ., 32, 1493-1497, 1998.

Pankow, J. F. and Asher, W. E.: SIMPOL.1: a simple group contribution method for predicting vapor pressures and enthalpies of vaporization of multifunctional organic compounds, Atmos. Chem. Phys., 8, 2773-2796, doi:10.5194/acp-8-27732008, 2008. 
Park, J. H., Hussam, A., Couasnon, P., Fritz, D., and Carr, P.W.: Experimental reexamination of selected partition coefficients from Rohrschneider's data set, Anal. Chem., 59, 1970-1976, 1987.

Raventos-Duran, T., Camredon, M., Valorso, R., Mouchel-Vallon, C., and Aumont, B.: Structure-activity relationships to estimate the effective Henry's law constants of organics of atmospheric interest, Atmos. Chem. Phys., 10, 7643-7654, doi:10.5194/acp10-7643-2010, 2010.

Roth, C. M., Goss, K.-U., and Schwarzenbach, R. P.: Adsorption of a diverse set of organic vapors on the bulk water surface, J. Colloid Interf. Sci., 252, 21-30, 2002.

Roth, C. M., Goss, K.-U., and Schwarzenbach, R. P.: Sorption of a diverse set of organic vapors to Diesel soot and road tunnel aerosol, Environ. Sci. Technol., 39, 6632-6637, 2005.

Schnitzler, E. G. and McDonald, K. M.: Characterization of lowtemperature vapour pressure estimates for secondary organic aerosol applications, Atmos. Environ., 56, 9-15, 2012.

Seinfeld, J. H. and Pandis, S. N.: Atmospheric Chemistry and Physics: From Air Pollution to Climate Change, 2nd Edition, John Wiley \& Sons Inc., NJ, 1232 pp., 2006.

Stenzel, A., Goss, K.-U., and Endo, S.: Prediction of partition coefficients for complex environmental contaminants: Validation of Cosmotherm, Absolv and SPARC, Environ. Toxicol. Chem., 33, 1537-1543, 2014.

Szmigielski R., Surratt, J. D., Gomez-Gonzalez, Y., Van der Veken, P., Kourtchev, I., Vermeylen, R., Blockhuys, F., Jaoui, M., Kleindienst, T. E., Lewandowski, M., Offenberg, J. H., Edney, E. O., Seinfeld, J. H., Maenhaut, W., and Claeys, M.: 3-methyl1,2,3-butanetricarboxylic acid: An atmospheric tracer for terpene secondary organic aerosol, Geophys. Res. Lett., 34, L24811, doi:10.1029/2007GL031338, 2007.

Valorso, R., Aumont, B., Camredon, M., Raventos-Duran, T., Mouchel-Vallon, C., Ng, N. L., Seinfeld, J. H., Lee-Taylor, J., and Madronich, S.: Explicit modelling of SOA formation from $\alpha$-pinene photooxidation: sensitivity to vapour pressure estimation, Atmos. Chem. Phys., 11, 6895-6910, doi:10.5194/acp-116895-2011, 2011.
Wang, C., Lei, Y. D., Endo, S., and Wania, F.: Measuring and modeling the salting out effect in ammonium sulfate solutions. Environ. Sci. Technol., 48, 13238-13245, doi:10.1021/es5035602, 2014.

Weininger, D.: SMILES, a chemical language and information system. 1. Introduction to methodology and encoding rules, J. Chem. Inf. Model., 28, 31-36, 1988.

You, Y., Renbaum-Wolff, L., Carreras-Sospedra, M., Hanna, S. J., Hiranuma, N., Kamal, S., Smith, M. L., Zhang, X., Weber, R. J., Shilling, J. E., Dabdub, D., Martin, S. T., and Bertram, A. K.: Images reveal that atmospheric particles can undergo liquidliquid phase separations, P. Natl. Acad. Sci., 109, 13188-13193, 2012.

Zhang, Q., Jimenez, J. L., Canagaratna, M. R., Allan, J. D., Coe, H., Ulbrich, I., Alfarra, M. R., Takami, A., Middlebrook, A. M., Sun, Y. L., Dzepina, K., Dunlea, E., Docherty, K., DeCarlo, P. F. Salcedo, D., Onasch, T., Jayne, J. T., Miyoshi, T., Shimono, A., Hatakeyama, S., Takegawa, N., Kondo, Y., Schneider, J., Drewnick, F., Borrmann, S., Weimer, S., Demerjian, K., Williams, P., Bower, K., Bahreini, R., Cottrell, L., Griffin, R. J., Rautiainen, J., Sun, J. Y., Zhang, Y. M., and Worsnop, D. R.: Ubiquity and dominance of oxygenated species in organic aerosols in anthropogenically-influenced Northern Hemisphere midlatitudes, Geophys. Res. Lett., 34, L13801, doi:10.1029/2007GL029979, 2007.

Zhang, X., Cappa, C. D., Jathar, S. H., McVay, R. C., Ensberg, J. J., Kleeman, M. J., and Seinfeld J. H.: Influence of vapor wall loss in laboratory chambers on yields of secondary organic aerosol, $\mathrm{P}$. Nat. Acad. Sci., 111, 5802-5807, 2014.

Zuend, A. and Seinfeld, J. H.: Modeling the gas-particle partitioning of secondary organic aerosol: the importance of liquidliquid phase separation, Atmos. Chem. Phys., 12, 3857-3882, doi:10.5194/acp-12-3857-2012, 2012.

Zuend, A., Marcolli, C., Peter, T., and Seinfeld, J. H.: Computation of liquid-liquid equilibria and phase stabilities: implications for RH-dependent gas/particle partitioning of organic-inorganic aerosols, Atmos. Chem. Phys., 10, 7795-7820, doi:10.5194/acp10-7795-2010, 2010. 